\title{
Perancangan Aplikasi Smart Zonasi Berbasis Location Based Service (LBS) SMAN di Kota Depok
}

\author{
Design of Smart Zoning Application Based on Location-Based Service (LBS) \\ Public High Schools in Depok City
}

Rheza Andika ${ }^{1}$, Diana Ikasari ${ }^{2}$, Widiastuti $^{3}$

${ }^{1,2,3}$ Program Studi Sistem Informasi, Universitas Gunadarma

\begin{tabular}{l}
\hline \hline ARTICLE INFO \\
\hline Article history: \\
DOI: \\
10.30595/pspfs.v1i.144 \\
Submitted: \\
April 26, 2021 \\
Accepted: \\
June 14, 2021 \\
Published: \\
Oct 31, 2021 \\
\hline
\end{tabular}

Keywords:

Aplication, Depok, LBS, Public High School

\begin{abstract}
The principle of the zoning system, which regulates regional zones for prospective students, is to bring the student's domicile closer to the school, where zoning is determined at every level by the Regional Government following its authority. In implementing zoning, it is important to pay attention to the amount of available capacity according to the availability of the number of school-age children at each level in the area. Depok City has 13 public high schools spread over 11 sub-districts that can accommodate 3,858 junior high school graduates. This became disproportionate to the number of outputs or junior high school graduates who were more than the available capacity. Based on the use of LBS technology, it was hoped that it would be easier to obtain information on the distance from the user's domicile to the destination school, where in the Depok there are 13 State Senior High Schools that are the reference. In designing the Location Based Services (LBS) application, SMAN Depok City used case diagrams, navigation structure designs, storyboards and database designs. The page design and database design results were expected to be used as a guide for programmers in making applications.
\end{abstract}

This work is licensed under a Creative Commons Attribution 4.0 International License.

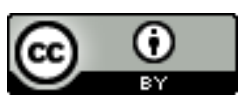

\section{Corresponding Author:}

Rheza Andika

Program Studi Sistem Informasi, Universitas Gunadarma

J1 Margonda Raya 100, Depok 53182 Telp. (021)-78881112

Email: rhezaandika@staff.gunadarma.ac.id

\section{PENDAHULUAN}

Pemerintah melalui Kementerian Pendidikan dan Kebudayaan (Kemendikbud) telah menerbitkan Peraturan Menteri Pendidikan dan Kebudayaan (Permendikbud) No. 14 Tahun 2019 tentang PPDB. Sistem zonasi yang mengatur mengenai zona wilayah bagi calon peserta didik Dimana Sistem Zonasi masuk kedalam empat program pokok kebijakan pendidikan "Merdeka Belajar" (Kemenristekdikti, 2019). Prinsipnya untuk mendekatkan domisili peserta didik dengan sekolah di mana penetapan zonasi dilakukan pada setiap jenjang oleh Pemerintah Daerah sesuai dengan kewenangannya. Dalam penerapan zonasi penting memperhatikan jumlah ketersediaan daya tampung disesuaikan dengan ketersediaan jumlah anak usia sekolah pada setiap jenjang di daerah tersebut. Kesepakatan secara tertulis antar Pemerintah Daerah dilakukan dalam penetapan zonasi pada setiap jenjang sekolah yang berada di daerah perbatasan provinsi atau kabupaten/kota. Pada PPDB tahun 2020, Dinas Pendidikan Provinsi Jawa Barat membuka empat jalur PPDB untuk jenjang SMA yang dibagi dua tahap. Tahap pertama, ada 3 jalur, yakni jalur Afirmasi 20\% yang terdiri dari Keluarga Ekonomi Tidak Mampu (KETM) 18\% dan tenaga medis Covid-19 2\%. Kemudian untuk jalur prestasi $25 \%$ yang terdiri dari prestasi nilai rapor $20 \%$ dan prestasi kejuaraan $5 \%$ dan terakhir jalur pindahan orangtua 5\%. Pada tahap kedua jalur yang digunakan menggunakan jalur zonasi dengan kuota 50\%. Kota Depok hanya memiliki 13 Sekolah Menengah Atas Negeri yang tersebar pada 11 kecamatan yang dapat menampung siswa 
lulusan SMP sebanyak 3.858 orang. Hal ini menjadi tidak sebanding dengan jumlah keluaran atau lulusan SMP yang lebih banyak dari daya tamping yang tersedia (Berita, 2020). Penerapan teknologi dalam memanfaatkan fungsi dari lokasi dengan menggunakan GPS (Global Positioning System) atau yang biasa disebut Location Based Services (LBS). Location based services adalah layanan berbasis lokasi atau istilah umum yang sering digunakan untuk menggambarkan teknologi yang digunakan untuk menemukan lokasi perangkat yang pengguna gunakan. Layanan ini menggunakan teknologi Global Positioning Service (GPS) dan cell-based location dari Google. LBS tersebut terdiri dari beberapa komponen di antaranya mobile devices, communication network, position component, dan service and content provider. Position component yang dimaksud adalah posisi pengguna harus ditentukan. Posisi ini dapat didapatkan dengan jaringan telekomunikasi atau dengan GPS, sedangkan service and content provider adalah penyedia layanan yang menyediakan layanan berbeda ke pengguna seperti pencarian rute, kalkulasi posisi, dan lainnya (Riswan Abidin, 2016).

Berdasarkan pemanfaatan teknologi LBS maka diharapkan dapat memudahkan dalam mendapatkan informasi jarak domisili pengguna dengan sekolah tujuan di mana pada kota Depok terdapat 13 Sekolah Menengan Atas Negeri yang menjadi rujukan.

\section{METODE PENELITIAN}

Tahapan yang dilakukan dalam penelitian ini mengambil dari model System Development Life Cycle (SDLC) hingga posisi tahapan perancangan (Budi dkk, 2020). Keuntungan penggunaan model SDLC ini salah satunya adalah dapat menentukan kebutuhan sistem dengan tepat dan terinci (Razaq dkk, 2014). terlihat seperti gambar 1.

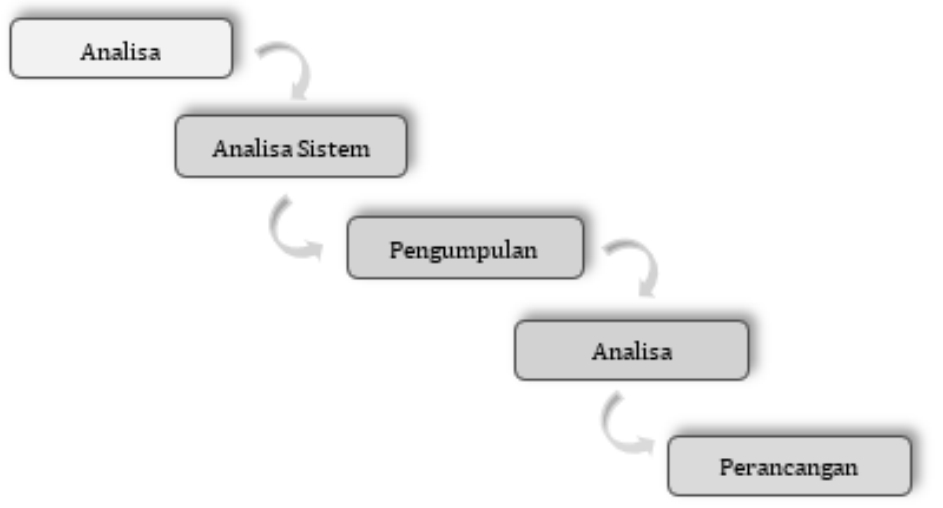

Gambar 1. Tahapan Penelitian

Berikut penjelasan dari setiap tahap penelitian yang dilakukan:

1. Analisa Masalah

Kegiatan yang dilakukan untuk memahami kondisi permasalahan yang ada agar dapat melakukan proses rancangan yang tepat demi mencapai solusi tepat.

2. Analisa Sistem

Tahap melakukan pemahaman tentang bagaimana sistem yang dibutuhkan dan akan dirancang berdasarkan hasil analisa masalah.

3. Pengumpulan Data

Kegiatan yang dilakukan adalah mengumpulkan data primer dengan metode survei dan melakukan pengamatan langsung ke lapangan dan wawancara dengan responden dan melakukan studi pustaka. Data yang didapatkan kemudian diolah dan dilakukan pemisahan untuk mendapatkan data dan informasi yang sesuai dengan bahasan dan lingkup penelitian.

4. Analisa Kebutuhan

Melakukan analisa kebutuhan fungsional yang meliputi fungsi-fungsi yang dibutuhkan oleh pengguna (user) dalam mengatasi masalah dan kebutuhan non-fungsional yang meliputi kebutuhan dalam pembuatan aplikasi baik dari sisi hardware maupun software.

5. Perancangan

Pada tahap ini akan dilakukan proses rancangan dengan tujuan memudahkan proses pembuatan aplikasi. Pemodelan sistem informasi menggunakan Unified Modelling Language (UML) yang digunakan untuk menentukan atau menggambarkan sebuah sistem software yang terkait dengan objek (Bruce, 2004). Kegiatan rancangan ini dimulai dengan membuat diagram use case, struktur navigasi, storyboard dan rancangan database dari aplikasi yang akan dibuat. 


\section{HASIL DAN PEMBAHASAN}

Tahapan penelitian dilakukan mulai dari analisa masalah hingga tahap perancangan seperti tertuang dalam sub bagian berikut.

\section{Analisa Masalah}

Sebagian besar peserta didik maupun orang tua peserta tidak mengetahui posisi SMAN yang ingin dituju. Berdasarkan PPDB kota Depok khususnya, mengetahui lokasi dan terlebih mengetahui jarak garis lurus antara lokasi tempat tinggal dan lokasi SMAN dibutuhkan untuk mendapatkan skor yang akurat. Sistem zonasi yang diberlakukan pemerintah kota Depok, membuat peserta didik dan orang tua peserta pedidik untuk mengetahui jarak garis lurus terdekat dengan lokasi tempat tinggal sebagai salah satu syarat penerimaan. Ketersediaan aplikasi pemetaan data SMAN wilayah kota Depok dalam bentuk sistem informasi geografis dan penghitungan jarak garis lurus dari tempat tinggal ke seluruh SMAN di wilayah kota Depok dapat membantu untuk memberikan rekomendasi. Langkah awal yang dibutuhkan adalah melakukan perancangan terhadap aplikasi tersebut.

\section{Analisa sistem}

Analisa sistem dari permasalahan adalah perlu dibuat suatu aplikasi yang dapat mempermudah siswa atau orang tua siswa untuk dapat mengetahui jarak garis lurus dari rumah ke SMAN yang dituju, diharapkan juga dapat membantu pihak sekolah dalam memberikan rekomendasi pilihan SMAN bagi para siswa agar kemungkinan untuk mendapat SMAN menjadi lebih berpeluang. Penghitungan jarak garis lurus dari tempat tinggal ke SMAN terdekat dengan menggunakan algoritma Haversine yang dipertimbangkan juga dengan perangkat-perangkat lain.

\section{Pengumpulan data}

Pada tahap pengumpulan data, metode yang digunakan adalah melakukan survei dan pengamatan langsung serta melengkapi detail data yang diambil menggunakan Key API Maps agar pemetaan sesuai dengan detail data dan lokasi SMAN. Data yang dikumpulkan adalah data spasial dan data non-spasial tentang informasi SMAN yang ada di wilayah kota Depok. Terdapat 13 SMAN yang berada di wilayah kota Depok dengan data SMAN, Nomor Pokok Sekolah Nasional (NPSN) dan kecamatan terlihat pada tabel 1.

Tabel 1. Daftar SMAN Wilayah Kota Depok

\begin{tabular}{llll}
\hline No & SMAN & NPSN & Kecamatan \\
\hline 1 & SMAN 1 Depok & 20223819 & Kec. Pancoran Mas \\
2 & SMAN 2 Depok & 20223818 & Kec. Sukmajaya \\
3 & SMAN 3 Depok & 20223817 & Kec. Sukmajaya \\
4 & SMAN 4 Depok & 20229166 & Kec. Tapos \\
5 & SMAN 5 Depok & 20229167 & Kec. Sawangan \\
6 & SMAN 6 Depok & 20229168 & Kec. Limo \\
7 & SMAN 7 Depok & 20268524 & Kec. Tapos \\
8 & SMAN 8 Depok & 20270492 & Kec. Cilodong \\
9 & SMAN 9 Depok & 20276187 & Kec. Cinere \\
10 & SMAN 10 Depok & 69851425 & Kec. Bojongsari \\
11 & SMAN 11 Depok & 69857937 & Kec. Beji \\
12 & SMAN 12 Depok & 69857938 & Kec. Cipayung \\
13 & SMAN 13 Depok & 69857939 & Kec. Cimanggis \\
\hline \multicolumn{4}{c}{ Tabel 1. Hasil Uji Coba }
\end{tabular}

\section{Analisa Kebutuhan}

Langkah yang perlu dilakukan sebelum perancangan adalah mengetahui semuan tentang kebutuhan fungsional dan non-fungsional sebagai dasar dalam melakukan perancangan.

a. Analisa Kebutuhan Fungsional

Kebutuhan fungsional yang didefinisikan sebagai kebutuhan yang berisi proses-proses yang nantinya akan dilakukan oleh sistem. Kebutuhan fungsional memiliki beberapa cakupan tentang perangkat lunak yang berhubungan dengan perancangan sistem yang akan dibuat yaitu sebagai berikut:

1. User atau pengguna dapat mencari Sekolah Menengah Atas Negeri di wilayah kota Depok.

2. User atau pengguna dapat mengetahui detail dan lokasi Sekolah Menengah Atas Negeri di wilayah kota Depok.

3. User atau pengguna dapat melihat tampilan peta beserta Sekolahsekolah menengah atas negeri yang ada di wilayah kota Depok. 
4. User atau pengguna dapat mengetahui jarak garis tarik lurus dari tempat tinggal (rumah) munuju Sekolah Menengah Atas Negeri tujuan di wilayah kota Depok.

b. Kebutuhan non-fungsional merupakan segala sesuatu yang dibutuhkan dan sangat diperlukan agar mendukung proses pembuatan aplikasi website. Dalam pembuatan aplikasi website ini membutuhkan beberapa Hardware dan Software yaitu sebagai berikut:

1. Kebutuhan Hardware yang digunakan, antara lain: Processor Intel(R) Celeron(R) CPU N2920@1.86GHz, Memory 2GB RAM, Operating System Windows 7 Ultimate 32 bit, dan Harddisk 1TB HDD.

2. Kebutuhan Software yang digunakan, antara lain: Start UML, Balsamiq Mockup, XAMPP, Sublime Text Editor, dan Google Chrome serta Key API Maps.

\section{Perancangan}

Perancangan dimulai dari melakukan perancangan usecase diagram, rancangan struktur navigasi, storyboard dan rancangan database.

\section{a. Rancangan Usecase Diagram}

Use case diagram rancangan ini merupakan sebuah model diagram yang terdiri dari admin dan user serta proses yang saling berinteraksi dan di dalamnya berisikan tentang informasi-informasi alur dari actor. Use case diagram admin dan user dapat dilihat pada gambar 2. Use case diagram ini menggambarkan secara garis besar mengenai sistem aplikasi.

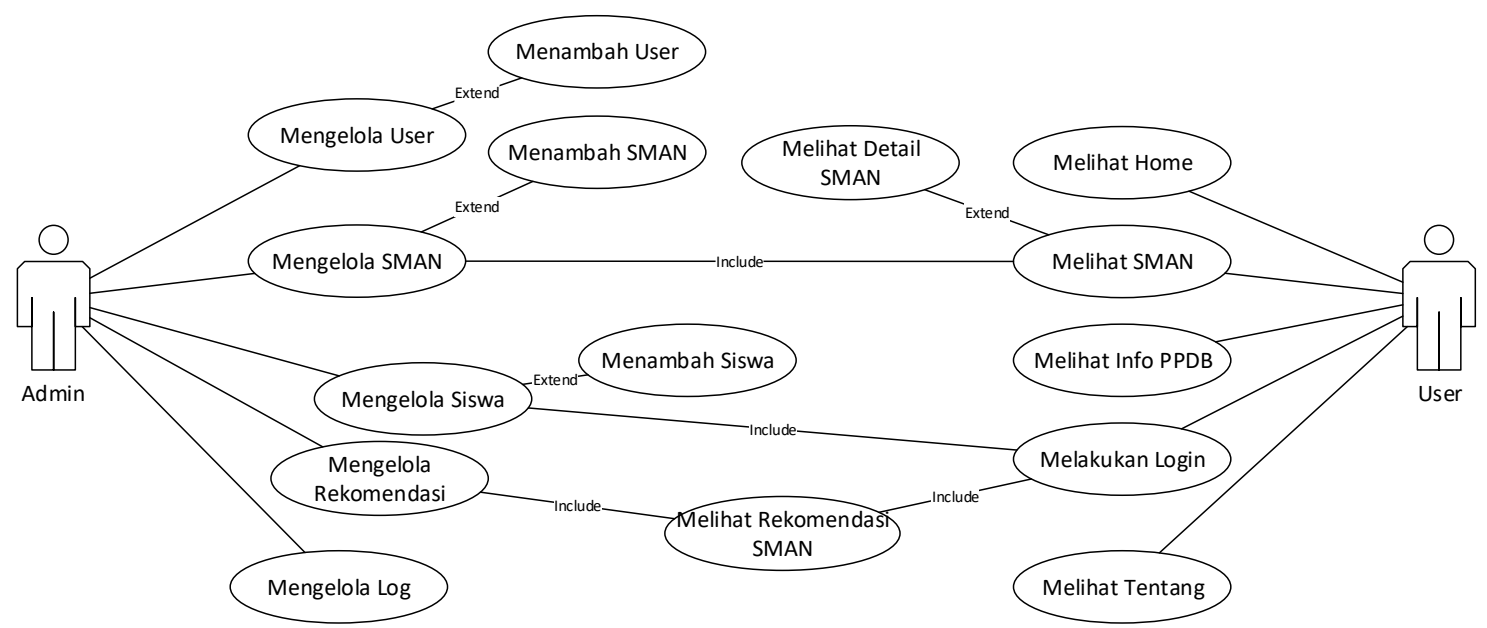

Gambar 2. Usecase Diagram Rancangan Aplikasi

\section{b. Rancangan Struktur Navigasi}

Pengguna dari aplikasi ini terdiri atas user (siswa, orang tua siswa dan pihak yang berkepentingan dengan aplikasi) dan admin (pengelola aplikasi). Gambar 3 adalah struktur navigasi user dan gambar 4 adalah struktur navigasi admin. Rancangan struktur navigasi untuk user seperti pada gambar x dimulai dari halaman Home, kemudian halaman Daftar SMAN di wilayah Kota Depok yang juga dapat dilihat detail informasi dari masing-masing SMAN, halaman Info PPDB berisi informasi mengenai kondisi PPDB terbaru di wilayah kota Depok, halaman Tentang dan halaman Rekomendasi yang dapat diakses setelah melakukan login. Halaman Rekomendasi memberikan perkiraan jarak garis lurus dari alamat tempat tinggal dengan alamat SMAN yang paling dekat secara keseluruhan terhadap semua SMAN yang ada.

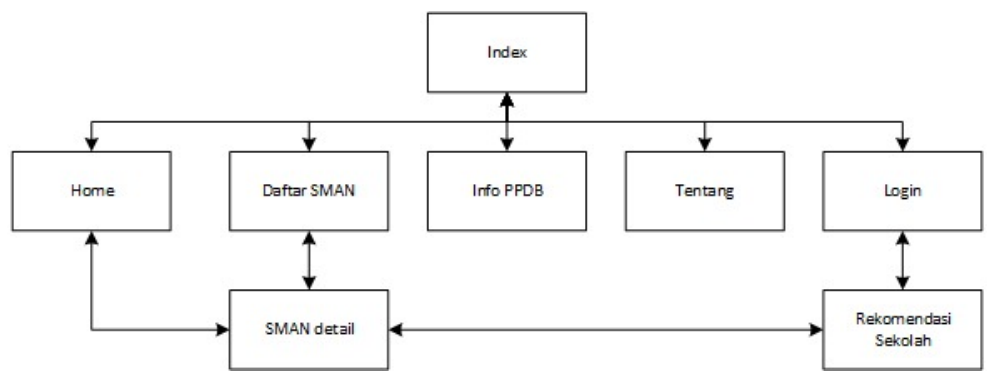

Gambar 3. Struktur Navigasi User 
Rancangan struktur navigasi untuk admin dimulai setelah melakukan login, aktivitas yang dapat dilakukan adalah mengelola data siswa, mengelola data sekolah, megelola data user, mengelola log aktivitas dan mengelola laporan hasil rekomendasi sekolah. Struktur navigasi admin terlihat pada gambar 4.

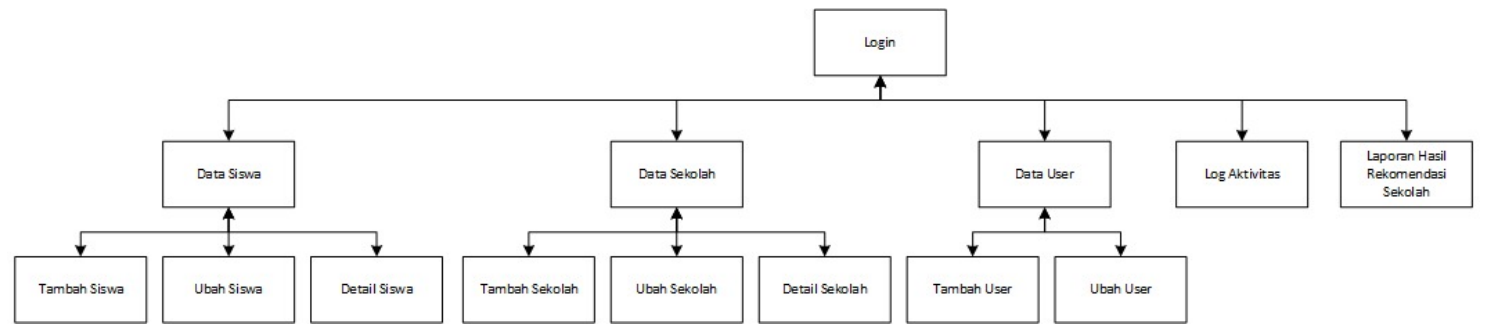

Gambar 4. Struktur Navigasi Admin

\section{c. Rancangan Storyboard}

Berdasarkan dari struktur navigasi user dan admin, dibuat storyboard yang akan sangat membantu pada saat pembuatan aplikasi. Storyboard aplikasi dibuat sesuai dengan struktur navigasinya, storyboard untuk user terlihat pada gambar $\mathrm{x}$ dan storyboard untuk admin terlihat pada gambar 5 .

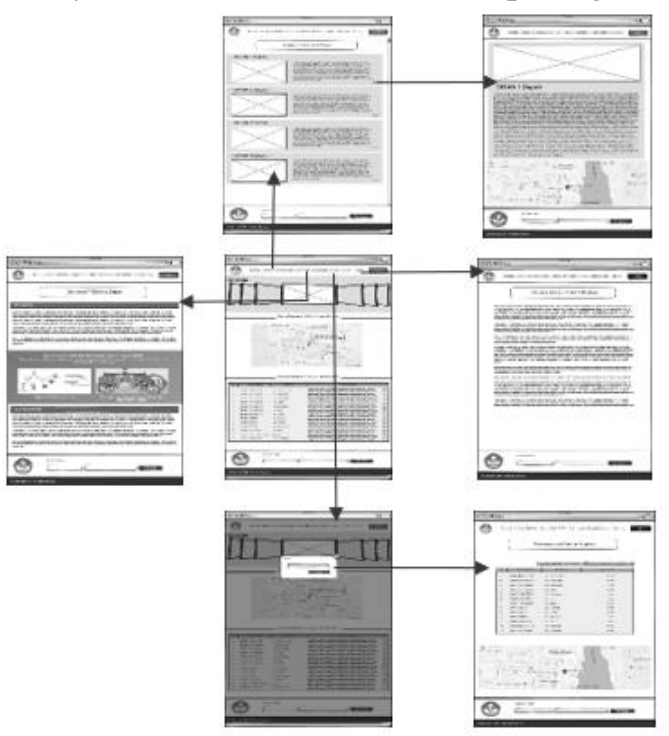

Gambar 5. Storyboard User

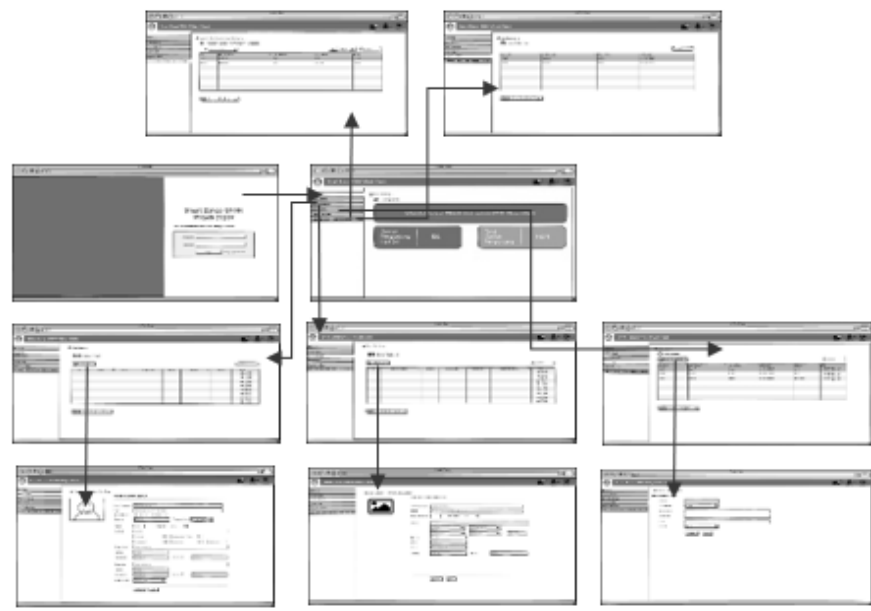

Gambar 6. Storyboard Admin 


\section{d. Rancangan Database}

Kebutuhan database dalam pembuatan aplikasi berdasarkan dari rancangan halaman yang tertuang dalam storyboard terdiri dari 3 tabel yaitu tabel admin, tabel sekolah, tabel siswa dan tabel user.

1) Tabel Admin

Tabel ini menyimpan data admin yang berfungsi mengelola tampilan dan isi dari aplikasi.

Tabel 2. Struktur Tabel Admin

\begin{tabular}{lll}
\hline \multicolumn{1}{c}{ Field } & \multicolumn{1}{c}{ Tipe Data } & \multicolumn{1}{c}{ Keterangan } \\
\hline ID_Admin & Int (2) & Primary Key \\
Username & VarChar (15) & \\
Password & Text & \\
Email & Text & \\
\hline
\end{tabular}

2) Tabel Sekolah

Tabel ini berfungsi untuk menyimpan data peta pada aplikasi yaitu tampilan peta SMA Negeri di kota Depok untuk melakukan insert, update dan delete.

Tabel 3. Struktur Tabel Sekolah

\begin{tabular}{lll}
\hline \multicolumn{1}{c}{ Field } & \multicolumn{1}{c}{ Tipe Data } & \multicolumn{1}{c}{ Keterangan } \\
\hline ID_Lokasi & Int (2) & Primary Key \\
Nama_Sekolah & VarChar (50) & \\
Website & VarChar (255) & \\
No_Contact & VarChar (16) & \\
Alamat_Sekolah & Text & \\
Longitude_S & VarChar (50) & \\
Latitude_S & VarChar (50) & \\
\hline
\end{tabular}

3) Tabel Siswa

Tabel ini berfungsi untuk menyimpan data-data siswa dari suatu sekolah yang aka diberikan rekomendasi pemilihan SMAN berdasarkan dari posisi jarak lurus kedekatan tempat tinggal dengan sekolah.

Tabel 3. Struktur Tabel User

\begin{tabular}{lll}
\hline \multicolumn{1}{c}{ Field } & \multicolumn{1}{c}{ Tipe Data } & \multicolumn{1}{c}{ Keterangan } \\
\hline ID_Siswa & Int (5) & Primary Key \\
Nama Siswa & VarChar (20) & \\
Alamat_Siswa & Text & \\
Longitude_R & VarChar (50) & \\
Latitude_R & VarChar (50) & \\
\hline
\end{tabular}

4) Tabel User

Tabel ini berfungsi untuk menyimpan data user yang akan melakukan login dan menyimpan data pada saat user membuat/mendaftarkan akun agar dapat login mengelola aplikasi.

Tabel 3. Struktur Tabel User

\begin{tabular}{lll}
\hline \multicolumn{1}{c}{ Field } & \multicolumn{1}{c}{ Tipe Data } & \multicolumn{1}{c}{ Keterangan } \\
\hline ID_User & Int (5) & Primary Key \\
First_Name & VarChar (20) & \\
Last_Name & VarChar (20) & \\
\hline
\end{tabular}

\section{KESIMPULAN}

Penelitian ini telah berhasil membuat menentukan kebutuhan fungsional maupun non fungsional untuk kegiatan selanjutnya yaitu pembuatan aplikasi. Penelitian ini menghasilkan rancangan halaman dan rancangan database yang dapat digunakan sebagai panduan programmer dalam membuat aplikasi smart zonasi berbasis location base service (LBS) SMAN di kota Depok.

\section{UCAPAN TERIMA KASIH}

Terima kasih peneliti sampaikan kepada Direktorat Riset dan Pengabdian Masyarakat Direktorat Jenderal Penguatan Riset dan Pengembangan Kementrian Riset, Teknologi dan Pendidikan Tinggi (Kemenristek Dikti) yang telah memberikan dana hibah Penelitian Unggulan Perguruan Tinggi. 


\section{DAFTAR PUSTAKA}

Berita, (2020). PPDB 2020/2021 Dilakukan Dua Tahap, Yuk Catat Setiap Tahapnya. URL: https://jabarprov.go.id/index.php/news/38052/2020/06/08/PPDB-20202021-Dilakukan-Dua-Tahap Yuk-CatatSetiap-Tahapnya.

Budi Asmanto, Mustika, Agustina Tria, (2020). Implementasi Metode SDLC pada Aplikasi Pengolahan Data Laporan Bulanan Kegiatan Puskesmas. JSAI, Bolume 3 Nomr 1, Januari 2020, ISSN: 2614-3062; E-ISSN: 2614-3054.

Bruce E. Wampler, (2004). The Essence of Object Oriented Programming with Java and UML.Addison-Wesley.

Dinas Pendidikan Kota Depok, (2020). Penerimaan Peserta Didik Baru 2020/2021. URL: https://disdik.depok.go.id/wp-content/uploads/2020/05/PPDB-KOTA-DEPOK-2020-FINAL-23-5-2020.pdf.

Kemenristekdikti, (2019). Peraturan Menteri Riset, Teknologi, dan Pendidikan Tinggi Republik Indonesia No. 44 Tahun 2019. Indonesia.

Razaq, Jefri Alfa dan Jananto, Arief, (2014). Sistem Informasi Publik Layanan Kesehatan menggunakan Metode Location Based Service di Kota Semarang. Jurnal Teknologi Informasi DINAMIK Volume 19, No.1, Januari 2014, ISSN: 0854-9524, pp. 59-67.

Riswan Abidin, (2016). Pengertian Location Based Services (LBS) dan Komponennya. URL: https://teknojurnal.com/pengertian-location-based-services-lbs-dan-komponennya. 